\title{
Comparison of single utility port video-assisted thoracoscopic surgery (VATS) and three-port VATS for non-small cell lung cancer
}

\author{
ZHONGRUI YE, BO ZHANG, YU CHEN and JIANG LIN \\ Department of Thoracic Surgery, Taizhou Hospital of Zhejiang Province, Taizhou, Zhejiang 317000, P.R. China
}

Received November 20, 2018; Accepted April 24, 2019

DOI: $10.3892 / \mathrm{ol} .2019 .10394$

\begin{abstract}
Clinical efficacy of single utility port videoassisted thoracoscopic surgery (VATS) and three-port VATS for patients with non-small cell lung cancer (NSCLC) was compared. A total of 156 patients with NSCLC who underwent VATS in Taizhou Hospital of Zhejiang Province from July 2015 to January 2017 were selected as subjects. They were randomly divided into group A $(n=74)$ and group B $(n=82)$, in which group A was treated with single utility port VATS and group B was treated with three-port VATS. Perioperative indicators such as operation time, intraoperative blood loss, postoperative drainage, removal of drainage tube, lymph node dissection, hospitalization time, postoperative complications, postoperative pain and postoperative quality of life were observed. Expression levels of CRP and IL-6 in serum were detected by enzyme-linked immunosorbent assay (ELISA). There was no significant difference in the operation time, postoperative drainage volume, drainage tube removal time and lymph node dissection between groups $\mathrm{A}$ and $\mathrm{B}(\mathrm{P}>0.05)$. Blood loss and hospitalization time in group A were significantly lower than those in group $\mathrm{B}(\mathrm{P}<0.001)$. VAS scores at 1-3 days after operation in group A were significantly lower than those in group $\mathrm{B}(\mathrm{P}<0.001)$. Levels of serum CRP and IL-6 at 1-7 days after operation in group A were significantly lower than those in group B $(\mathrm{P}<0.001)$. Incidence of complication in group A was not significantly different from that in group $\mathrm{B}(\mathrm{P}>0.05)$. Overall quality of life scores of group A and $\mathrm{B}$ were significantly lower than the preoperative scores $(\mathrm{P}<0.001)$. Overall status score of group A was significantly higher than that of group $\mathrm{B}(\mathrm{P}<0.001)$. Clinical efficacies of single utility port VATS and three-port VATS were similar.
\end{abstract}

Correspondence to: Dr Zhongrui Ye, Department of Thoracic Surgery, Taizhou Hospital of Zhejiang Province, 150 Ximen Street, Linhai, Taizhou, Zhejiang 317000, P.R. China

E-mail: ruq3ae@163.com; tzyezr@163.com

Key words: non-small cell lung cancer, single utility port video-assisted thoracoscopic surgery, three-port video-assisted thoracoscopic surgery, clinical efficacy
Single utility port VATS can reduce trauma during surgery, reduce stress response, relieve postoperative pain, and facilitate the recovery of postoperative quality of life.

\section{Introduction}

Lung cancer is one of the most common malignant tumors and is the leading cause of cancer-related deaths. In 2012, lung cancer accounts for approximately $12.9 \%$ of all cancers (1). The most common type of lung cancer is non-small cell lung cancer (NSCLC). NSCLC accounts for 85-90\% of lung cancer. NSCLC is mainly divided into adenocarcinoma and squamous cell carcinoma subtypes, which are derived from bronchial mucosa epithelium (2). At present, surgical treatment is the most effective and important method for early NSCLC (3). Although the use of minimally invasive surgery in clinical practice has increased in recent years, thoracotomy is still the most common method of lobectomy (4). Studies have shown that video-assisted thoracoscopic surgery (VATS) brings more benefits to patients with early NSCLC compared with conventional thoracotomy, including reduced hospital stay, relief of recent postoperative pain, and less postoperative complications (5). VATS lobectomy consists of several incisions or ports, usually 3-4. With the development of laparoscopic instrument technology, VATS is gradually reduced from multiple incisions to double incision, namely single utility port thoracoscopic surgery (6). Since 2010, single utility port VATS lobectomy has become a new area of minimally invasive surgery (7). Single utility port VATS is a less invasive surgical procedure. With single utility port VATS, thoracic surgery can be performed through a small incision of approximately $4 \mathrm{~cm}$ in diameter. This technique has been increasingly accepted because of its remarkable clinical effect (8). Compared with conventional VATS, single utility port VATS not only have the advantage of reducing surgical trauma, but also reduces postoperative pain and prompts recovery (9). Clinical efficacy of single utility port VATS has been extensively studied, but studies on the postoperative stress response and the impact on quality of life (physical, functional and social) in 3 months after surgery are rare. In this study, single utility port VATS and three-port VATS were performed in patients with NSCLC to compare the clinical efficacy. Postoperative stress response and quality of life were also compared. 


\section{Patients and methods}

General information. One hundred and fifty-six patients with NSCLC who underwent VATS in Taizhou Hospital of Zhejiang Province (Taizhou, China) from July 2015 to January 2017 were selected as subjects. Patients were randomly divided into group A ( $n=74)$ and group B $(n=82)$. Group A was treated with single utility port VATS and group B was treated with threeport VATS. There were 43 males and 31 females in group A,

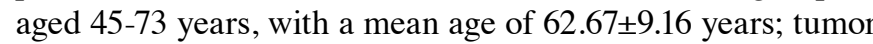
diameter was $1.4-4.8 \mathrm{~cm}$, with mean diameter of $2.81 \pm 1.16 \mathrm{~cm}$; TNM staging: 59 cases in stage I, 15 cases in stage II; pathological types: 59 cases of adenocarcinoma, 10 cases of squamous cell carcinoma, 5 cases of adenosquamous carcinoma. There were 59 males and 23 females in group B, aged 41-72 years, with a mean age of $61.83 \pm 8.26$ years; tumor diameter was $1.3-4.5 \mathrm{~cm}$, with a mean diameter of $2.86 \pm 1.35 \mathrm{~cm}$; TNM staging: 64 cases in stage I, 18 cases in stage II; pathological types: 61 cases of adenocarcinoma, 14 cases of squamous cell carcinoma, 7 cases of adenosquamous carcinoma.

Inclusion and exclusion criteria. Inclusion criteria: Preoperative pathological examination confirmed NSCLC (10); No distant metastases under examination of CT, color Doppler ultrasound, MRI and other imaging examinations, TNM stage was stage I-II; no previous history of chemotherapy and radiation therapy; first diagnosis; aged 18-75 years; Eastern Cancer Cooperative Group (ECOG) (11) physical status was $0-1$, expected survival time $\geq 12$ months; no major organ dysfunction.

Exclusion criteria: History of previous thoracoscopic surgery; extensive pleural adhesions; difficulty in maintaining single-lung ventilation during surgery; combined with other tumors, severe liver and kidney dysfunction, connective tissue disease, endocrine and metabolic diseases, hematopoietic dysfunction, infectious diseases; mental illness or family history of mental illness.

This study was approved by The Ethics Committee of Taizhou Hospital of Zhejiang Province. Patients who participated in this research had complete clinical data. The signed informed consents were obtained from the patients or the guardians.

Treatment. Compound anesthesia was performed. After intubation of the double lumen tube, single lung ventilation was performed into the pleural cavity. Lateral position $\left(90^{\circ}\right)$ on the healthy side was used. After disinfection, observation hole was made in the 7th intercostal space of the midline of the iliac crest. A $2 \mathrm{~cm}$ incision was made and thoracoscope was placed. For single utility port VATS, an incision $(4 \mathrm{~cm})$ was made between the 4 th and 5 th ribs of the iliac crest. For threeport VATS, $2 \mathrm{~cm}$ incision (main operation hole) was made in the fifth intercostal space of the iliac crest, and another $2 \mathrm{~cm}$ incision (sub-operation hole) was made in the 7th intercostal space of the anterior subscapular line. Mediastinal pleura was opened, and the lower ligament of the lower lung was dissected. According to the condition of the resected lung lobe, the venous, arterial, and bronchial organs were dissected by a single-type lobectomy method. The (articular head) intra-cavity linear cutting and closing device was used to close the detachment. Lobes were removed, and mediastinal lymph nodes were also removed. After that, the chest cavity was flushed, the blood was stopped, the drainage tube was placed, and the chest was closed layer by layer.

Observation indicators. i) Perioperative indicators such as operation time, intraoperative blood loss, postoperative drainage, removal of drainage tube, lymph node dissection, hospitalization time and postoperative complications were observed.

ii) The degree of pain was assessed by visual analog scale (VAS) (12) from 1 to 7 days postoperatively (T1-T7). VAS score of 0 indicated no pain, and VAS score of 10 indicated the most severe pain. The higher the VAS score, the more severe the pain.

iii) Venous blood was taken from the study subjects before and 1-7 days after surgery (T1-T7) under fasting conditions. Blood was centrifuged at $670.8 \mathrm{x}$ g at $20-25^{\circ} \mathrm{C}$ for $10 \mathrm{~min}$ to separate serum. Expression of CRP and IL-6 in serum was detected by enzyme-linked immunosorbent assay (ELISA) (13). Human CRP and IL-6 ELISA kits (Thermo Fisher Scientific Co., Ltd., Shanghai, China) were used. All operations were performed in strict accordance with manufacturer's instructions. No reagent was added into the blank control well. After adding samples, the plate was covered with film and incubated at $37^{\circ} \mathrm{C}$ for $1 \mathrm{~h}$. After that, the plate was washed and $80 \mu \mathrm{l}$ affinity chain enzyme was added into each well, followed by incubation at $37^{\circ} \mathrm{C}$ for $30 \mathrm{~min}$. After that, substrate A and B $(50 \mu \mathrm{l})$ was added, followed by incubation at $37^{\circ} \mathrm{C}$ for $10 \mathrm{~min}$. Then each well was added with $50 \mu 1$ stop solution. OD value of each well was measured at $450 \mathrm{~nm}$ by using a fully automated enzyme label analyzer (Miguel Molecular Instruments Co., Ltd., Shanghai, China), and the expression levels of CRP and IL-6 were calculated.

iv) Functional assessment of cancer treatment - The lung cancer questionnaire (FACT-L) (14) was used to assess the quality of life of patients before and 3 months after surgery. FACT-L contains 27 items, including body, function, situation and social fields. Each item has a 5-level scale (0-4 points, $0=$ no, $4=$ very much).

Statistical analysis. Statistical analysis was performed using SPSS 19.0 (IBM Corp, Armonk, NY, USA). Measurement data were expressed as mean \pm standard deviation, and the intergroup comparisons of measurement data in accordance with the normal distribution were compared by $\mathrm{t}$-test. Comparison with a group before and after treatment was performed by paired t-test. Count data were expressed as number of cases/ percentage [n (\%)]. Chi-square test was used to compare count data between groups. ANOVA was used for comparison between multiple groups and the post hoc test was LSD test. $\mathrm{P}<0.05$ was considered to indicate a statistically significant difference.

\section{Results}

Baseline data of groups A and B. Groups A and B showed no significant difference in sex, age, body mass index (BMI), smoking and drinking history, lesion location, tumor diameter, TNM stage, pathological type, pathological 
Table I. Baseline data of groups A and B [n (\%)]/(mean \pm SD).

\begin{tabular}{|c|c|c|c|c|}
\hline Items & Group A $(n=74)$ & Group B (n=82) & $\mathrm{t} / \chi^{2}$ value & P-value \\
\hline Sex & & & 3.293 & 0.070 \\
\hline Male & $43(58.11)$ & $59(71.95)$ & & \\
\hline Female & $31(41.89)$ & $23(28.05)$ & & \\
\hline Age & $62.67 \pm 9.16$ & $61.83 \pm 8.26$ & 0.602 & 0.548 \\
\hline $\mathrm{BMI}\left(\mathrm{kg} / \mathrm{m}^{2}\right)$ & $20.47 \pm 3.18$ & $20.04 \pm 3.07$ & 0.859 & 0.392 \\
\hline History of smoking & & & 2.212 & 0.137 \\
\hline Yes & $30(40.54)$ & $43(52.44)$ & & \\
\hline No & $44(59.46)$ & $39(47.56)$ & & \\
\hline Drinking history & & & 0.562 & 0.454 \\
\hline Yes & $22(29.73)$ & $29(35.37)$ & & \\
\hline No & $52(70.27)$ & $53(64.63)$ & & \\
\hline Lesion & & & 0.054 & 0.816 \\
\hline Upper left lobe & $16(21.62)$ & $20(24.39)$ & & \\
\hline Left lower lobe & $8(10.81)$ & $9(10.98)$ & & \\
\hline Right upper lobe & $17(22.97)$ & $17(20.73)$ & & \\
\hline Right middle lobe & $10(13.51)$ & $10(12.20)$ & & \\
\hline Right lower lobe & $23(31.08)$ & $26(31.71)$ & & \\
\hline Tumor diameter $(\mathrm{cm})$ & $2.81 \pm 1.16$ & $2.86 \pm 1.35$ & 0.247 & 0.805 \\
\hline TNM staging & & & 0.066 & 0.797 \\
\hline Phase I & $59(79.73)$ & $64(78.05)$ & & \\
\hline Phase II & $15(20.27)$ & $18(21.95)$ & & \\
\hline Pathological type & & & 0.537 & 0.464 \\
\hline Adenocarcinoma & $59(79.73)$ & $61(74.39)$ & & \\
\hline Squamous cell carcinoma & $10(13.51)$ & $14(17.07)$ & & \\
\hline Adenosquamous carcinoma & $5(6.76)$ & $7(8.54)$ & & \\
\hline Degree of pathological differentiation & & & 0.105 & 0.746 \\
\hline Highly differentiated & $17(22.97)$ & $22(26.83)$ & & \\
\hline Medium differentiation & $47(63.51)$ & $43(52.44)$ & & \\
\hline Low differentiation & $10(13.51)$ & $17(20.73)$ & & \\
\hline $\operatorname{ALT}(\mathrm{U} / \mathrm{l})$ & $27.47 \pm 5.18$ & $26.91 \pm 6.33$ & 0.600 & 0.549 \\
\hline $\operatorname{AST}(\mathrm{U} / \mathrm{l})$ & $17.18 \pm 4.27$ & $17.69 \pm 4.82$ & 0.696 & 0.487 \\
\hline Glu (mmol/l & $5.97 \pm 0.38$ & $6.06 \pm 0.47$ & 1.306 & 0.193 \\
\hline
\end{tabular}

ALT, alanine aminotransferase; AST, aspartate aminotransferase; SD, standard deviation.

Table II. Comparison of perioperative indicators between groups A and B (mean \pm SD).

\begin{tabular}{lccr}
\hline Items & Group A (n=74) & Group B (n=82) & t value \\
\hline Operation time (min) & $142.63 \pm 52.73$ & $153.66 \pm 51.84$ & 1.316 \\
Intraoperative blood loss (ml) & $136.47 \pm 42.71$ & $173.41 \pm 49.27$ & 4.978 \\
Postoperative drainage (ml) & $681.21 \pm 44.85$ & $692.54 \pm 38.41$ & 1.699 \\
Drainage tube removal time (days) & $4.28 \pm 0.93$ & $4.51 \pm 1.12$ & 0.190 \\
Number of lymph node dissections (a) & $14.17 \pm 4.18$ & $13.87 \pm 4.41$ & 1.387 \\
Hospital stay (days) & $9.31 \pm 1.82$ & $11.34 \pm 1.32$ & 0.435 \\
\hline
\end{tabular}

$\mathrm{SD}$, standard deviation.

differentiation, alanine aminotransferase (ALT), aspartate aminotransferase $(\mathrm{AST})$ and blood sugar $(\mathrm{Glu})(\mathrm{P}<0.05)$ (Table I).
Comparison of perioperative indicators between groups $A$ and $B$. There was no significant difference between the groups in operation time, postoperative drainage volume, 


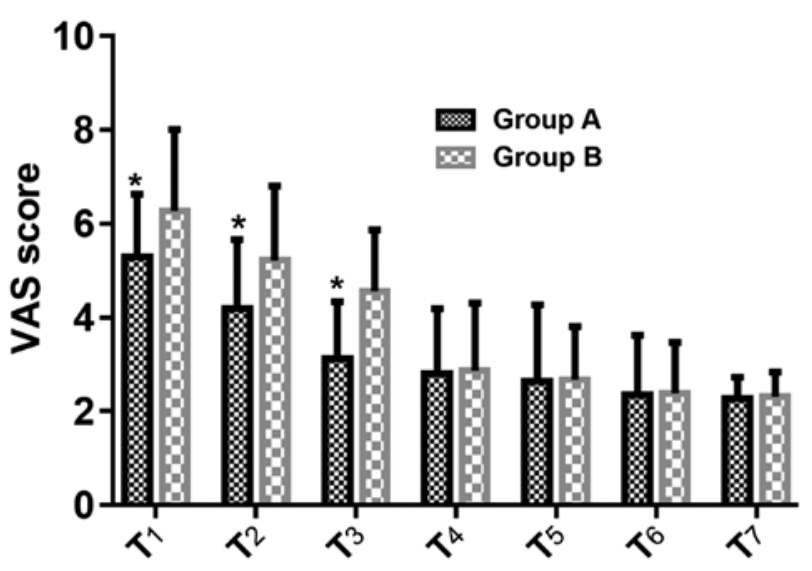

Figure 1. Comparison of VAS scores at 1 and 7 days after operation between groups $\mathrm{A}$ and $\mathrm{B}$. ${ }^{\mathrm{P}} \mathrm{P}<0.001$.

Table III. Comparison of VAS scores at 1 and 7 days after operation between groups A and B (mean $\pm \mathrm{SD})$.

\begin{tabular}{lcccc}
\hline $\begin{array}{l}\text { Time } \\
\text { points }\end{array}$ & $\begin{array}{c}\text { Group A } \\
(\mathrm{n}=74)\end{array}$ & $\begin{array}{c}\text { Group B } \\
(\mathrm{n}=82)\end{array}$ & t value & P-value \\
\hline $\mathrm{T} 1$ & $5.29 \pm 1.34$ & $6.28 \pm 1.73$ & 3.685 & $<0.001$ \\
$\mathrm{~T} 2$ & $4.19 \pm 1.47$ & $5.22 \pm 1.58$ & 4.170 & $<0.001$ \\
$\mathrm{~T} 3$ & $3.13 \pm 1.21$ & $4.56 \pm 1.31$ & 6.303 & $<0.001$ \\
$\mathrm{~T} 4$ & $2.81 \pm 1.38$ & $2.87 \pm 1.44$ & 0.374 & 0.708 \\
$\mathrm{~T} 5$ & $2.64 \pm 1.63$ & $2.68 \pm 1.13$ & 0.689 & 0.492 \\
$\mathrm{~T} 6$ & $2.35 \pm 1.27$ & $2.39 \pm 1.08$ & 0.546 & 0.604 \\
$\mathrm{~T} 7$ & $2.27 \pm 0.46$ & $2.31 \pm 0.53$ & 0.938 & 0.350 \\
\hline
\end{tabular}

Table IV. Comparison of serum CRP expression levels between groups $A$ and $B$ before and 1-7 days after surgery (mean \pm SD, $\mathrm{mg} / \mathrm{l})$.

\begin{tabular}{lrrrc}
\hline $\begin{array}{l}\text { Time } \\
\text { points }\end{array}$ & $\begin{array}{c}\text { Group A } \\
(\mathrm{n}=74)\end{array}$ & $\begin{array}{c}\text { Group B } \\
(\mathrm{n}=82)\end{array}$ & t value & P-value \\
\hline Before & & & & \\
operation & $3.15 \pm 1.13$ & $3.29 \pm 1.27$ & 0.724 & 0.470 \\
$\mathrm{~T}_{1}$ & $18.64 \pm 3.27$ & $24.52 \pm 2.41$ & 12.870 & $<0.001$ \\
$\mathrm{~T}_{2}$ & $14.05 \pm 2.29$ & $17.49 \pm 3.36$ & 7.392 & $<0.001$ \\
$\mathrm{~T}_{3}$ & $10.59 \pm 1.15$ & $13.25 \pm 2.18$ & 9.382 & $<0.001$ \\
$\mathrm{~T}_{4}$ & $8.25 \pm 1.32$ & $11.23 \pm 2.57$ & 8.963 & $<0.001$ \\
$\mathrm{~T}_{5}$ & $7.67 \pm 1.59$ & $9.67 \pm 2.03$ & 6.799 & $<0.001$ \\
$\mathrm{~T}_{6}$ & $5.27 \pm 1.24$ & $7.22 \pm 1.94$ & 7.390 & $<0.001$ \\
$\mathrm{~T}_{7}$ & $4.38 \pm 1.76$ & $6.37 \pm 1.89$ & 6.784 & $<0.001$ \\
\hline
\end{tabular}

drainage tube removal time and lymph node dissection $(\mathrm{P}>0.05)$. The blood loss and hospitalization time in group $\mathrm{A}$ were significantly lower than those in group $\mathrm{B}(\mathrm{P}<0.001)$ (Table II).

Comparison of VAS scores at 1 and 7 days after operation between groups $A$ and $B$. VAS scores of group A were
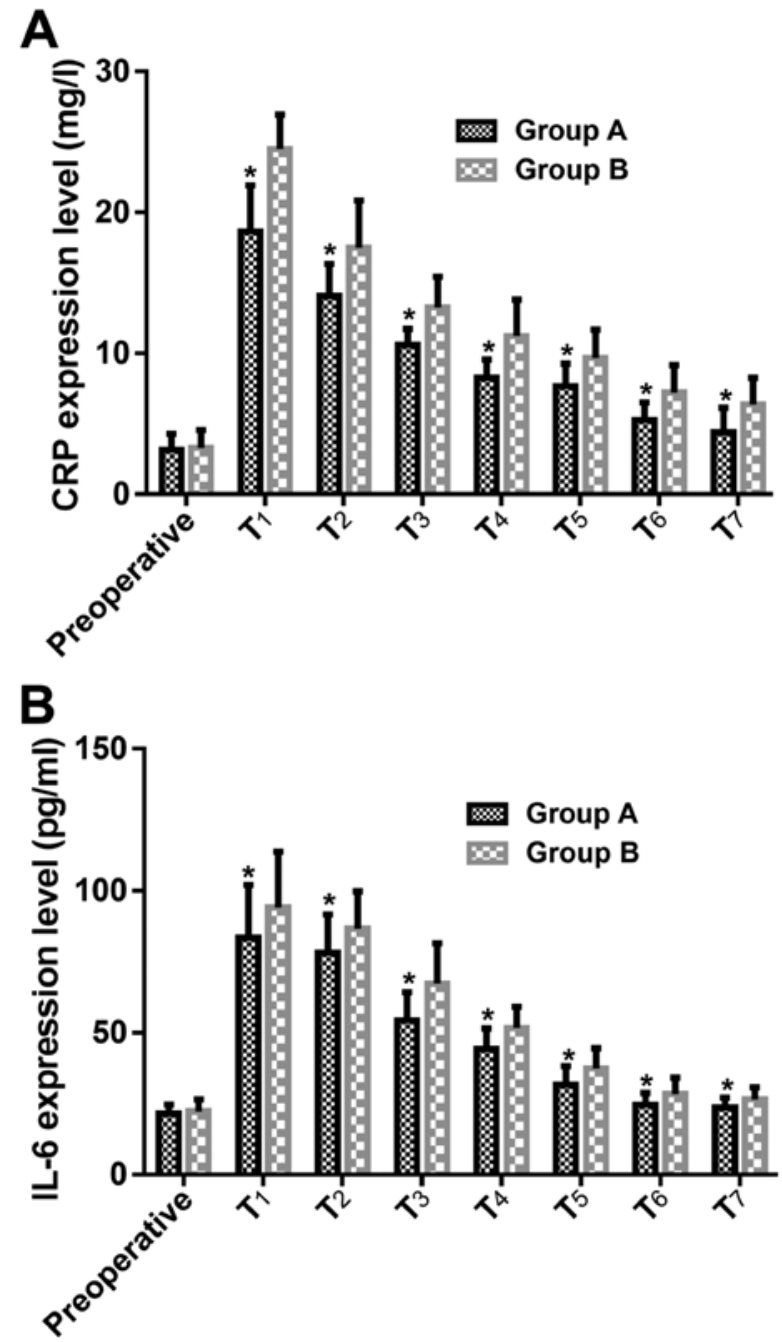

Figure 2. Comparison of serum (A) CRP and (B) IL-6 expression levels between groups $\mathrm{A}$ and $\mathrm{B}$ before and 1 to 7 days after operation. ${ }^{*} \mathrm{P}<0.001$.

Table V. Comparison of serum IL-6 expression levels between groups A and B before and 1 to 7 days after surgery (mean $\pm \mathrm{SD}, \mathrm{pg} / \mathrm{l})$.

\begin{tabular}{llllr}
\hline Time points & $\begin{array}{c}\text { Group A } \\
(\mathrm{n}=74)\end{array}$ & $\begin{array}{c}\text { Group B } \\
(\mathrm{n}=82)\end{array}$ & $\mathrm{t}$ value & P-value \\
\hline Before & & & & \\
operation & $21.53 \pm 3.18$ & $22.37 \pm 4.18$ & 1.401 & 0.163 \\
$\mathrm{~T}_{1}$ & $83.47 \pm 18.63$ & $94.18 \pm 19.67$ & 3.482 & $<0.001$ \\
$\mathrm{~T}_{2}$ & $78.20 \pm 13.47$ & $86.74 \pm 13.08$ & 4.005 & $<0.001$ \\
$\mathrm{~T}_{3}$ & $54.43 \pm 9.85$ & $67.36 \pm 14.22$ & 6.533 & $<0.001$ \\
$\mathrm{~T}_{4}$ & $44.27 \pm 7.31$ & $51.64 \pm 7.58$ & 6.167 & $<0.001$ \\
$\mathrm{~T}_{5}$ & $31.74 \pm 6.52$ & $37.41 \pm 7.15$ & 5.156 & $<0.001$ \\
$\mathrm{~T}_{6}$ & $24.58 \pm 4.28$ & $28.47 \pm 5.74$ & 4.757 & $<0.001$ \\
$\mathrm{~T}_{7}$ & $23.69 \pm 3.51$ & $26.51 \pm 4.28$ & 4.471 & $<0.001$ \\
\hline & & & &
\end{tabular}

ssignificantly lower than those of group B at 1-3 days after operation $(\mathrm{P}<0.001)$. There was no significant difference between groups $\mathrm{A}$ and $\mathrm{B}$ at 4-7 days after operation $(\mathrm{P}>0.05)$ (Table III and Fig. 1). 
Table VI. Comparison of postoperative complications between groups A and B [n (\%)].

\begin{tabular}{lcccccc}
\hline Groups & $\mathrm{n}$ & Pulmonary infection & Lung leak & Atelectasis & Arrhythmia & Incidence rate $(\%)$ \\
\hline A & 74 & $0(0.00)$ & $1(1.35)$ & $2(2.70)$ & $6(8.11)$ & 12.16 \\
B & 82 & $2(2.44)$ & $1(1.22)$ & $3(3.66)$ & $8(9.76)$ & 17.07 \\
$\chi^{2}$ value & - & - & - & - & - & 0.746 \\
P-value & - & - & - & - & - & 0.388 \\
\hline
\end{tabular}

Table VII. Comparison of quality of life between groups A and B before and after operation (mean \pm SD).

\begin{tabular}{|c|c|c|c|c|c|c|c|c|}
\hline \multirow[b]{2}{*}{ Status scores } & \multicolumn{2}{|c|}{ Group A $(n=74)$} & \multirow[b]{2}{*}{$\mathrm{t}$ value } & \multirow[b]{2}{*}{ P-value } & \multicolumn{2}{|c|}{ Group B $(n=82)$} & \multirow[b]{2}{*}{ t value } & \multirow[b]{2}{*}{ P-value } \\
\hline & $\begin{array}{c}\text { Before } \\
\text { operation }\end{array}$ & $\begin{array}{c}\text { After } \\
\text { operation }\end{array}$ & & & $\begin{array}{c}\text { Before } \\
\text { operation }\end{array}$ & $\begin{array}{c}\text { After } \\
\text { operation }\end{array}$ & & \\
\hline Physical status & $19.35 \pm 2.81$ & $19.25 \pm 1.83$ & 0.257 & 0.798 & $19.36 \pm 2.68$ & $19.07 \pm 2.13$ & 0.743 & 0.459 \\
\hline Functional status & $21.03 \pm 2.37$ & $20.62 \pm 2.13$ & 1.107 & 0.270 & $20.71 \pm 2.16$ & $19.85 \pm 2.38$ & 1.513 & 0.132 \\
\hline Emotional status & $19.82 \pm 2.47$ & $19.32 \pm 1.94$ & 1.369 & 0.173 & $19.44 \pm 2.02$ & $18.86 \pm 1.92$ & 1.833 & 0.069 \\
\hline Social status & $18.36 \pm 4.28$ & $17.33 \pm 3.25$ & 1.649 & 0.101 & $18.49 \pm 4.17$ & $17.52 \pm 2.86$ & 1.737 & 0.084 \\
\hline Additional status & $24.05 \pm 5.36$ & $23.16 \pm 4.03$ & 1.142 & 0.256 & $23.51 \pm 4.13$ & $22.72 \pm 3.11$ & 1.384 & 0.168 \\
\hline Overall status & $102.15 \pm 7.35$ & $98.31 \pm 5.23$ & 3.662 & $<0.001^{\mathrm{a}}$ & $101.36 \pm 8.52$ & $95.13 \pm 5.68$ & 5.509 & $<0.001^{\mathrm{a}}$ \\
\hline
\end{tabular}

${ }^{a} \mathrm{P}<0.001$ indicates statistical significance.

Comparison of serum CRP and IL-6 expression levels between groups $A$ and $B$ before and 1 to 7 days after operation. There was no significant difference in serum CRP and IL-6 expression levels between groups A and B before operation ( $\mathrm{P}>0.05)$. Levels of serum CRP and IL-6 in group A were significantly lower than those in group $\mathrm{B}$ at 1-7 days after operation $(\mathrm{P}<0.001)$ (Tables IV and V; Fig. 2).

Comparison of postoperative complications between groups $A$ and $B$. In group A, 1 case $(1.35 \%)$ had lung leak, 2 cases $(2.70 \%)$ had atelectasis, 6 cases $(8.11 \%)$ had arrhythmia, and the complication rate was $12.16 \%$. In group B, 2 cases $(2.44 \%)$ had pulmonary infection, 1 case $(1.22 \%)$ had lung leak, 3 cases $(3.66 \%)$ had atelectasis, 8 cases $(9.76 \%)$ had arrhythmia, and the complication rate was $17.07 \%$. There was no significant difference in the incidence of complications between groups $\mathrm{A}$ and $\mathrm{B}(\mathrm{P}>0.05)$ (Table VI).

Comparison of quality of life between groups $A$ and $B$ before and after operation. There was no significant difference in physical, functional, emotional, social and additional status scores between groups A and B before and after operation $(\mathrm{P}>0.05)$. The overall status score of groups A and B after operation was significantly lower than that before operation $(\mathrm{P}<0.001)$, and the overall status score of group A after operation was significantly higher than that of group $B$ $(\mathrm{P}<0.001)$ (Table VII).

\section{Discussion}

The number of lung cancer patients has increased in recent years and lung cancer has become the leading cause of human death. For the early treatment of lung cancer, surgical resection is still the main method. Traditional thoracotomy causes severe incision and trauma, and postoperative pain is serious, which makes the quality of life of lung cancer patients greatly reduced (15). With the continuous development of endoscopic techniques, minimally invasive treatment has become a hot research topic that could reduce postoperative complications and improve the quality of life of patients with NSCLC (16). Single utility port VATS is operated with only one incision. With single utility port VATS, thoracoscope and instruments are operated in one hole during the operation, and the trauma is small, and blood vessels and intercostal nerve damage are avoided, and postoperative pain is also lighter (17). Thus, single utility port VATS therapy is receiving increasing attention in clinical treatment of NSCLC.

Previous studies have shown that the surgical incision of single utility port VATS is mostly between 4.0 and $7.0 \mathrm{~cm}$ (18). The length of the incision in this study is about 4.0 to $5.0 \mathrm{~cm}$, which is similar to previous studies. Three-port VATS usually requires three incisions. The first incision is generally used as an observation hole between the 7th and 8th intercostals, and second incision is used as the main operation hole in the 5th or 6th intercostal space of the ankle line, and the 3rd incision is a sub-operation hole (19) made between the rear line and the shoulder line.

Single utility port VATS is a modified 2-incision technique in which the operating hole is located at the 4th intercostal space of the incision, and the incision is large enough for the operator to accurately position the endoscopic stapler on the fragile pulmonary vessel; and with less incision on the chest wall, the intercostal nerve injury and intercostal traction could be minimized during surgery (18). Results of this study 
showed that blood loss in group A was significantly lower than that in group B. The VAS score was significantly lower in group A than that in group B at 1-3 days after operation, suggesting that single utility port VATS performed for patients with NSCLC can reduce intraoperative blood loss, reduce trauma during surgery and reduce postoperative pain, this result is similar with the study of Zhu et al (20). Single utility hole VATS is a single-hole operation and ribs are not pulled, so thoracic damage and pain are relatively light. This may be because single utility port VATS is without rib traction, which causes less pain to the patient's thorax, while 3 holes from the posterior tibial incision as a secondary operation hole. There are many layers of muscles in the thoracic back, abundant blood supply and nerve distribution, narrow rib space, and thus easy to bleed during the incision. An important indicator of successful operation in radical surgery for lung cancer is the hilar mediastinal lymphadenectomy. Effective removal of the hilar and mediastinal lymph nodes during surgery can not only provide reference for postoperative pathological staging, but also affect the prognosis of patients $(21,22)$. The results of Chang et al (23) showed that the total number of single utility port or double-port VATS lymph node dissection was similar. Results of this study showed that there was no significant difference in the number of lymph node dissections between groups A and B. Therefore, single utility port VATS can also achieve the purpose of treating NSCLC.

IL-6 is an acute phase mediator involved in B cell stimulation. Peak value of IL-6 is usually reached $2 \mathrm{~h}$ after surgery, and then rapidly decreases in patients without complications. CRP is one of the representatives of acute phase proteins and provides a reliable screening test for acute phase reactants. CRP level reaches peaks between 24 and $72 \mathrm{~h}$ after surgery, and its level may continue to rise for approximately 2 weeks $(24,25)$. Therefore, IL- 6 and CRP can be used as objective biochemical markers reflecting surgical tissue trauma. Results of this study showed that levels of serum CRP and IL-6 in group A were significantly lower than those in group B at 1 to 7 days after surgery, indicating that single utility port VATS can reduce the surgical trauma and reduce stress response in patients with NSCLC. In addition, results of this study showed that incidence of complication in group A was not significantly different from that in group B, but the length of hospital stay was significantly shorter than that in group B, indicating that single utility port VATS can shorten hospital stay. Dai et al (26) showed that single-pore VATS have the advantages of reducing blood loss and reducing postoperative pain compared with dual-pore VATS. Surgery-induced intercostal nerve injury is an important cause of pain in patients (27). Overall incision length of single utility port VATS is significantly reduced compared with three-port VATS, and intercostal nerve damage is reduced, and the amount of intraoperative blood loss is also reduced. Therefore, complications such as lung infections are inhibited, and hospital stay is shortened.

Quality of life of cancer patients has become an important criterion for the evaluation of tumor treatment efficacy (28). Our 3-month follow-up study showed that there was no significant difference in physical, functional, emotional, social, and additional status scores between the preoperative and postoperative levels in groups A and B. Overall status of group A and B was significantly worse than that of preoperative conditions.
Overall status of group A was significantly higher than that of group B, suggesting that VATS will affect the quality of life of patients with NSCLC, but the effect of single utility port VATS on short-term quality of life is better than that of three-port VATS, possibly due to the smaller trauma caused by single utility port VATS. Möller et al (29) followed up patients undergoing lung cancer surgery and found that the SF-36 quality of life score decreased 6 months after surgery, which confirmed that thoracic surgery would affect the quality of life of patients, however, the report also showed Age, extent of resection, and subsequent adjuvant therapy were closely associated with a decline in quality of life associated with physical condition at 6 months postoperatively. Although the differences between the single utility port and three-port VATS perioperative indexes were observed in this study, longterm follow-up results are lacking. The recurrence of cancer was not investigated. Thus, studies with longer follow-up are still required.

In conclusion, clinical efficacies of single utility port VATS and three-port VATS were similar. Single utility port VATS can reduce trauma during surgery, reduce stress response, relieve postoperative pain, and facilitate the recovery of postoperative quality of life.

\section{Acknowledgements}

Not applicable.

\section{Funding}

This study was supported by Taizhou Science and Technology Bureau (no. 14sf03).

\section{Availability of data and materials}

The datasets used and/or analyzed during the present study are available from the corresponding author on reasonable request.

\section{Authors' contributions}

ZY and BZ conceived and designed the study. YC collected the patient data. ZY and JL analyzed and interpreted the patient data regarding the non-small cell lung cancer. ZY and BZ performed the experiment of single utility port VATS and three-port VATS. ZY was a major contributor in writing the manuscript. All authors read and approved the final manuscript.

\section{Ethics approval and consent to participate}

This study was approved by The Ethics Committee of Taizhou Hospital of Zhejiang Province (Taizhou, China). Patients who participated in this research had complete clinical data. The signed informed consents were obtained from the patients or the guardians.

\section{Patient consent for publication}

Not applicable. 


\section{Competing interests}

The authors declare that they have no competing interests.

\section{References}

1. Chen W, Zheng R, Zeng H and Zhang S: Epidemiology of lung cancer in China. Thorac Cancer 6: 209-215, 2015.

2. Bhaumik S, Ahmad F and Das BR: Molecular binary classification of NSCLC: miR-375 is a potential biomarker to differentiate SQCC from ADCC in Indian NSCLC patients. App Cancer Res 37: 28, 2017.

3. Higuchi M, Yaginuma H, Yonechi A, Kanno R, Ohishi A, Suzuki H and Gotoh M: Long-term outcomes after videoassisted thoracic surgery (VATS) lobectomy versus lobectomy via open thoracotomy for clinical stage IA non-small cell lung cancer. J Cardiothorac Surg 9: 88, 2014.

4. Paul S, Sedrakyan A, Chiu YL, Nasar A, Port JL, Lee PC, Stiles BM and Altorki NK: Outcomes after lobectomy using thoracoscopy vs thoracotomy: A comparative effectiveness analysis utilizing the Nationwide Inpatient Sample database. Eur J Cardiothorac Surg 43: 813-817, 2013.

5. Yang HX, Woo KM, Sima CS, Bains MS, Adusumilli PS, Huang J, Finley DJ, Rizk NP, Rusch VW, Jones DR, et al: Long-term survival based on the surgical approach to lobectomy for clinical stage I nonsmall cell lung cancer: Comparison of robotic, video-assisted thoracic surgery, and thoracotomy lobectomy. Ann Surg 265: 431-437, 2017.

6. Ng CSH, Gonzalez-Rivas D, D'Amico TA and Rocco G: Uniportal VATS - a new era in lung cancer surgery. J Thorac Dis 7: 1489-1491, 2015.

7. Gonzalez-Rivas D, de la Torre M, Fernandez R and Mosquera VX Single-port video-assisted thoracoscopic left upper lobectomy. Interact Cardiovasc Thorac Surg 13: 539-541, 2011.

8. Anile M, Diso D, De Giacomo T, Rendina EA and Venuta F: Uniportal thoracoscopic lobectomy. Ann Thorac Surg 96: 745, 2013.

9. Abouarab AA, Rahouma M, Kamel M, Ghaly G and Mohamed A: Single versus multi-incisional video-assisted thoracic surgery: A systematic review and meta-analysis. J Laparoendosc Adv Surg Tech A 28: 174-185, 2018.

10. Reck M, Popat S, Reinmuth N, De Ruysscher D, Kerr KM and Peters S; ESMO Guidelines Working Group: Metastatic non-small-cell lung cancer (NSCLC): ESMO Clinical Practice Guidelines for diagnosis, treatment and follow-up. Ann Oncol 25 (Suppl 3): iii27-iii39, 2014.

11. Hanna NH, Dahlberg SE, Kolesar JM, Aggarwal C, Hirsch FR, Ramalingam SS and Schiller JH: Three-arm, randomized, phase 2 study of carboplatin and paclitaxel in combination with cetuximab, cixutumumab, or both for advanced non-small cell lung cancer (NSCLC) patients who will not receive bevacizumab-based therapy: An Eastern Cooperative Oncology Group (ECOG) study (E4508). Cancer 121: 2253-2261, 2015.

12. Sato J, Ohtori S, Orita S, Yamauchi K, Eguchi Y, Ochiai N, Kuniyoshi K, Aoki Y, Nakamura J, Miyagi M, et al: Radiographic evaluation of indirect decompression of mini-open anterior retroperitoneal lumbar interbody fusion: Oblique lateral interbody fusion for degenerated lumbar spondylolisthesis. Eur Spine J 26 : 671-678, 2017

13. Sapan HB, Paturusi I, Jusuf I, Patellongi I, Massi MN, Pusponegoro AD, Arief SK, Labeda I, Islam AA, Rendy L, et al: Pattern of cytokine (IL-6 and IL-10) level as inflammation and anti-inflammation mediator of multiple organ dysfunction syndrome (MODS) in polytrauma. Int J Burns Trauma 6: 37-43, 2016.

14. Ferrell B, Sun V, Hurria A, Cristea M, Raz DJ, Kim JY, Reckamp K, Williams AC, Borneman T, Uman G, et al: Interdisciplinary palliative care for patients with lung cancer. $\mathrm{J}$ Pain Symptom Manag 50: 758-767, 2015.

15. Bendixen M, Jørgensen OD, Kronborg C, Andersen C and Licht PB: Postoperative pain and quality of life after lobectomy via video-assisted thoracoscopic surgery or anterolateral thoracotomy for early stage lung cancer: A randomised controlled trial. Lancet Oncol 17: 836-844, 2016.
16. Hao Z, Cai Y, Fu S, Zhang N and Fu X: Comparison study of postoperative pain and short-term quality of life between uniportal and three portal video-assisted thoracic surgery for radical lung cancer resection. Zhongguo Fei Ai Za Zhi 19: 122-128, 2016 (In Chinese).

17. Hirai K, Takeuchi S and Usuda J: Single-incision thoracoscopic surgery and conventional video-assisted thoracoscopic surgery: a retrospective comparative study of perioperative clinical outcomes. Eur J Cardiothorac Surg 49 (Suppl 1): i37-i41, 2016.

18. Wang BY, Liu CY, Hsu PK, Shih CS and Liu CC: Single-incision versus multiple-incision thoracoscopic lobectomy and segmentectomy: A propensity-matched analysis. Ann Surg 261: 793-799, 2015.

19. Shen Y, Wang H, Feng M, Xi Y, Tan L and Wang Q: Singleversus multiple-port thoracoscopic lobectomy for lung cancer: a propensity-matched study. Eur J Cardiothorac Surg 49 (Suppl 1): i48-i53, 2016.

20. Zhu Y, Liang M, Wu W, Zheng J, Zheng W, Guo Z, Zheng B, $\mathrm{Xu} \mathrm{G}$ and Chen C: Preliminary results of single-port versus triple-port complete thoracoscopic lobectomy for non-small cell lung cancer. Ann Transl Med 3: 92, 2015.

21. Wang W, Yin W, Shao W, Jiang G, Wang Q, Liu L, Liu D, Wang Z, Zhu Z, Chen H, et al: Comparative study of systematic thoracoscopic lymphadenectomy and conventional thoracotomy in resectable non-small cell lung cancer. J Thorac Dis 6: 45-51, 2014.

22. Finley R, Mayo J, Donagh C, Leo J, Grant K, Lam S and English J: P1. 16-34 The impact of pathology, staging and operative resection on survival and CT evidence of recurrence of early NSCLC. J Thorac Oncol 13: S640-S641, 2018.

23. Chang JM, Kam KH, Yen YT, Huang WL, Chen W, Tseng YL, Wu MH, Lai WW and Gonzalez-Rivas D: From biportal to uniportal video-assisted thoracoscopic anatomical lung resection: A single-institute experience. Medicine (Baltimore) 95: e5097, 2016.

24. Leung KL, Lai PBS, Ho RLK, Meng WC, Yiu RY, Lee JF and Lau WY: Systemic cytokine response after laparoscopic-assisted resection of rectosigmoid carcinoma: A prospective randomized trial. Ann Surg 231: 506-511, 2000.

25. Fretland AA, Sokolov A, Postriganova N, Kazaryan AM, Pischke SE, Nilsson PH, Rognes IN, Bjornbeth BA, Fagerland MW, Mollnes TE, et al: Inflammatory response after laparoscopic versus open resection of colorectal liver metastases: Data from the Oslo-CoMet Trial. Medicine (Baltimore) 94: e1786, 2015.

26. Dai F, Meng S, Mei L, Guan C and Ma Z: Single-port videoassisted thoracic surgery in the treatment of non-small cell lung cancer: A propensity-matched comparative analysis. J Thorac Dis 8: 2872-2878, 2016.

27. Mier JM, Chavarin A, Izquierdo-Vidal C, Fibla JJ and Molins L: A prospective study comparing three-port video-assisted thoracoscopy with the single-incision laparoscopic surgery (SILS) port and instruments for the video thoracoscopic approach: A pilot study. Surg Endosc 27: 2557-2560, 2013.

28. Quinten C, Martinelli F, Coens C, Sprangers MA, Ringash J, Gotay C, Bjordal K, Greimel E, Reeve BB, Maringwa J, et al; Patient Reported Outcomes and Behavioral Evidence (PROBE) and the European Organization for Research and Treatment of Cancer (EORTC) Clinical Groups: A global analysis of multitrial data investigating quality of life and symptoms as prognostic factors for survival in different tumor sites. Cancer 120: 302-311, 2014.

29. Möller A and Sartipy U: Predictors of postoperative quality of life after surgery for lung cancer. J Thorac Oncol 7: 406-411, 2012.

This work is licensed under a Creative Commons Attribution-NonCommercial-NoDerivatives 4.0 International (CC BY-NC-ND 4.0) License. 